\title{
Cholinergic Inhibition of Ventral Midbrain Dopamine Neurons
}

\author{
Christopher D. Fiorillo and John T. Williams \\ Vollum Institute, L474, Oregon Health Sciences University, Portland, Oregon 97201
}

\begin{abstract}
Muscarinic acetylcholine receptors are common throughout the CNS. The predominant subtypes in the brain are positively coupled to phosphoinositide hydrolysis and have been found to modulate multiple conductances. Muscarinic receptor activation is most often observed to be excitatory because of suppression of various potassium conductances. Here it is reported that three distinct effects of muscarinic receptor activation can be observed in isolation from one another, depending on the duration of receptor activation and the concentration of agonist. Brief activation of muscarinic receptors, as is likely to occur with normal synaptic transmission, hyperpolarized dopamine neurons of the
\end{abstract}

ventral midbrain through a calcium-activated potassium conductance. With repeated or persistent activation of muscarinic receptors, the hyperpolarizing response was entirely desensitized in the absence of any change in resting membrane potential. With sustained activation by higher concentrations of agonist, dopamine neurons were depolarized. This demonstrates that muscarinic receptors can mediate very diverse, and even opposing, postsynaptic effects on neurons depending on the pattern of acetylcholine release.

Key words: IPSP; calcium-activated potassium (sK); phosphoinositide; calcium stores; heterologous desensitization; ryanodine
Five subtypes of muscarinic acetylcholine receptors have been cloned to date, all of which fall into one of two categories of G-protein-coupled receptor (for review, see Caulfield, 1993). The M2-like receptor family (m2, m4) inhibit adenylyl cyclase and $\mathrm{Ca}^{2+}$ channels and activate inwardly rectifying $\mathrm{K}^{+}$channels. M1-type receptors $(\mathrm{m} 1, \mathrm{~m} 3$, and $\mathrm{m} 5)$ are the more common type of muscarinic receptor in the CNS. These receptors are positively coupled to phospholipase $\mathrm{C}$, which catalyzes the production of inositol trisphosphate $\left(\mathrm{IP}_{3}\right)$ and diacylglycerol, which can then trigger release of calcium from intracellular stores and activation of protein kinase $\mathrm{C}$, respectively. M1 type receptors have been found to modulate a surprisingly large number of conductances, even in a single neuron. In CA1 pyramidal neurons of the hippocampus, muscarinic receptors have been shown to block at least four potassium conductances (Cole and Nicoll, 1984; Nakajima et al., 1986; Madison et al., 1987), to activate at least two potassium conductances (Segal 1982; Wakamori et al., 1993; Zhang et al., 1992), and to activate a cation conductance (Colino and Halliwell, 1993). The transduction mechanisms mediating most of these effects are poorly understood. Likewise, it is not known to what extent these conductances are modulated simultaneously or whether they are modulated selectively under distinct conditions. It has been shown that the concentration of muscarinic agonist can determine which of three potassium conductances are blocked (Madison et al., 1987). In addition, muscarinic receptors may produce activation before inhibition of potassium conductance or conductances (Segal 1982; Wakamori et al., 1993). It is not known which factors determine whether excitation or inhibition predominates. We have investigated these issues in dopamine neurons of the ventral midbrain.

Previous work has shown that stimulation of muscarinic receptors activates dopamine neurons (Scarnati et al., 1986; Lacey et al., 1990; Gronier and Rasmussen, 1998) (for review, see Kitai et al., 1999). Superfusion of muscarine in a ventral midbrain slice activates M1-type receptors to produce depolarization of dopamine

Received June 27, 2000; revised Aug. 3, 2000; accepted Aug. 9, 2000.

This work was supported by National Institutes of Health Grants DA 04523 and DA 05793. We thank Drs. Carlos Paladini and Hitoshi Morikawa for helpful comments on this manuscript.

Correspondence should be addressed to Dr. John T. Williams, Vollum Institute, L474, Oregon Health Sciences University, 3181 Southwest Sam Jackson Park Road, Portland, OR 97201. E-mail: williamj@ohsu.edu.

Dr. Fiorillo's present address: Institute for Physiology, University of Fribourg, Rue de Musèe 5, CH 1700 Fribourg, Switzerland.

Copyright (C) 2000 Society for Neuroscience $0270-6474 / 00 / 207855-06 \$ 15.00 / 0$ neurons, most likely through inhibition of a potassium conductance and an increase in a cation conductance (Lacey et al., 1990). Like the M1-type of muscarinic receptor, metabotropic glutamate receptors 1 and 5 (mGluR1 and mGluR5) couple to phosphoinositide (PI) hydrolysis and mobilization of calcium from intracellular stores. It was recently shown in dopamine neurons of the ventral midbrain that mGluR1 mediates a slow IPSP through mobilization of calcium from intracellular stores (Fiorillo and Williams, 1998). The hyperpolarizing action of mGluRs was readily desensitized by slow application of agonist, lost with whole-cell recording techniques using high calcium-buffering solutions, and blocked by a nonspecific action of the $\mathrm{GABA}_{\mathrm{A}}$ receptor antagonist bicuculline. For all of these reasons, an analogous hyperpolarizing action of muscarinic receptors could have gone undetected in previous studies. The present study demonstrates that rapid application of acetylcholine activates muscarinic receptors on dopamine neurons to release calcium from internal stores, which subsequently increases an apamin-sensitive potassium conductance.

\section{MATERIALS AND METHODS}

Slice preparation. Intracellular recordings were made in horizontal slices (250- to 300- $\mu \mathrm{m}$-thick) of ventral midbrain from adult male Wistar rats (150-200 gm). Details of the method of slice preparation and recording have been published (Williams et al., 1984). Recordings were made from submerged slices in a chamber $(0.5 \mathrm{ml})$ superfused with physiological saline at a rate of $1.5 \mathrm{ml} / \mathrm{min}$ and maintained at $35^{\circ} \mathrm{C}$. The solution was equilibrated with $95 \% \mathrm{O}_{2}$ and $5 \% \mathrm{CO}_{2}$ and contained (in mM): $126 \mathrm{NaCl}$, $2.5 \mathrm{KCl}, 1.2 \mathrm{MgCl}_{2}, 2.4 \mathrm{CaCl}_{2}, 1.4 \mathrm{NaH}_{2} \mathrm{PO} 4,25 \mathrm{NaHCO} 3$, and 11 D-glucose.

Recordings. Intracellular recordings were made with an Axoclamp 2A amplifier (Axon Instruments, Foster City, CA) and were used for studies involving cholinergic IPSPs and hyperpolarizing responses to pressureapplied acetylcholine. Microelectrodes (50-70 M $\Omega$ ) were filled with $2 \mathrm{M}$ $\mathrm{KCl}$. During experiments, the membrane potential was adjusted to between -60 and $-70 \mathrm{mV}$ to prevent spontaneous action potentials. Dopamine neurons of the ventral tegmental area (VTA) and substantia nigra pars compacta $(\mathrm{SNc})$ were identified by their electrical properties (Johnson and North, 1992). Dopamine neurons fired spontaneous, relatively longduration action potentials at a rate of $1-5 \mathrm{~Hz}$, each followed by a large afterhyperpolarization. Dopamine neurons also displayed a timedependent depolarization in response to hyperpolarizing current injection. No differences were observed in responses of neurons in the SNc and the VTA; the data were pooled. Whole-cell recordings were made with an Axopatch 1D and were used for studies involving mGluR IPSCs and iontophoresis of acetylcholine. Patch pipettes contained (in mM): 115 K-methylsulfate, $20 \mathrm{NaCl}, 1.5 \mathrm{MgCl}_{2}$, 5 HEPES, 0.1 EGTA, 2 ATP, 0.5 GTP, and 10 phosphocreatine. Electrode resistance was 2-5 M $\Omega$; access resistance ranged between 7 and $15 \mathrm{M} \Omega$ and was compensated by $80 \%$. The somata of individual cells were visualized with an upright microscope and infrared illumination. Dopamine neurons were identified both visually 

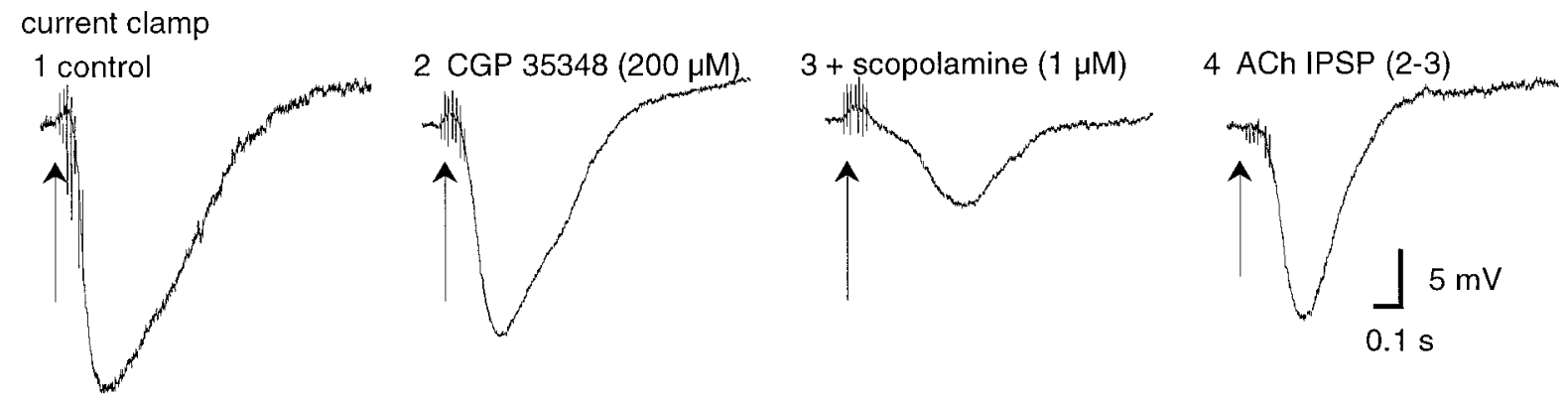

Figure 1. A slow IPSP blocked by scopolamine. This figure is an intracellular recording of membrane potential. A train of electrical stimuli were applied at the arrow to evoke transmitter release. Traces 1-3 are each the average of three trials. 1, The slow IPSP in the presence of ionotropic receptor antagonists (glutamate and GABA). 2, Addition of the GABA $\mathrm{B}_{\mathrm{B}}$ receptor antagonist CGP $35348(200 \mu \mathrm{M})$ blocked only a small fraction of the IPSP in this cell. 3, Addition of the muscarinic receptor antagonist scopolamine $(1 \mu \mathrm{M})$ blocks an early component of the IPSP, leaving a later component that was mediated by glutamate acting on mGluRs. 4, The scopolamine-sensitive component of the IPSP, isolated by subtraction of trace 3 from trace 2 .

and by the presence of large H-currents at hyperpolarized potentials. The current in response to iontophoretic application of acetylcholine and synaptically released transmitter was measured at a holding potential of $-50 \mathrm{mV}$.

Synaptic responses. Synaptic potentials or currents were evoked with bipolar tungsten stimulating electrodes with a tip separation of 300-600 $\mu \mathrm{m}$. A train of $8-10$ stimuli of $400 \mu \mathrm{sec}$ at $0.3-1.5 \mathrm{~mA}$ was delivered at 66 $\mathrm{Hz}(15 \mathrm{msec}$ interval) every $60 \mathrm{sec}$. Stimulating electrodes were placed within $1 \mathrm{~mm}$ caudal of the recording site. A cocktail of antagonists was present in experiments on synaptic potentials. This included picrotoxin (100 $\mu \mathrm{M} ; \mathrm{GABA})$, strychnine (1 $\mu \mathrm{M}$; glycine), NBQX (5 $\mu \mathrm{M} ;$ AMPA), MK-801 (50-100 $\mu \mathrm{M}$ pretreatment only; NMDA), eticlopride (100 nM; D2), and CGP 56999a (100-300 nM; GABA $\left.{ }_{\mathrm{B}}\right)$ or CGP $35348(200 \mu \mathrm{M}$; $\mathrm{GABA}_{\mathrm{B}}$ ).

Drugs. Drugs were applied to the slice by superfusion, except acetylcholine, which was applied by pressure ejection (in experiments with intracellular recording) or by iontophoresis (in experiments with whole-cell recording). For pressure ejection, acetylcholine (3-30 mM) in $0.09 \% \mathrm{NaCl}$ solution was applied from patch pipettes (1.5 $\mu \mathrm{m}$ tip diameter) for 3-300 msec at 20 psi using a Picospritzer II. Pipettes were moved closer to the cell body until a hyperpolarizing response was elicited. The duration of the ejections was usually adjusted to maximize the hyperpolarizing response while minimizing the depolarizing response; this helped to prevent desensitization of the hyperpolarizing response. In all experiments with pressure ejection, hexamethonium $(200 \mu \mathrm{M})$ was present to block nicotinic acetylcholine receptors. For iontophoresis, acetylcholine (1 M) was applied $(50-100 \mathrm{nA}, 100 \mathrm{msec})$ from a microelectrode placed within $10 \mu \mathrm{m}$ of the cell body. Hexamethonium was not used; the nicotinic response did not interfere with the slower muscarinic response and was used as a measure of acetylcholine release from the iontophoretic pipette.

Apamin, $( \pm)$ muscarine chloride, picrotoxin, $( \pm)$ scopolamine, strychnine, and tetrodotoxin were from Sigma (St. Louis, MO). Acetylcholine chloride, caffeine, $S(-)$-eticlopride, hexamethonium, and MK-801 were from Research Biochemicals International (Natick, MA). 1,2,3,4tetrahydro-6-nitro-2,3,-dioxo-benzo[f]quinoxaline (NBQX) and (S)-3,5dihydroxyphenylglycine (DHPG) were from Tocris Cookson (St. Louis, MO). Ryanodine was from Calbiochem (San Diego, CA). CGP 56999a and CGP 35348 were a gift from Novartis Pharmaceuticals (Basel, Switzerland).

Data analysis. Values are given as arithmetic means \pm SEM. The percent change produced by a superfused drug was calculated as the mean amplitude of three to five responses after equilibrium had been reached $(5-10 \mathrm{~min})$ relative to the mean of five responses before drug superfusion. Paired comparisons were made using a Wilcoxon signed-rank test.; $p<$ 0.05 was considered as a significant difference. Unless stated otherwise, all drug effects quantified are statistically significant.

\section{RESULTS}

\section{Synaptic potentials}

Stimulating electrodes were positioned caudal to the dopamine cell region, in an attempt to stimulate ascending cholinergic fibers. In the presence of ionotropic receptor antagonists and a $\mathrm{GABA}_{\mathrm{B}}$ receptor antagonist, a train of 5-10 stimuli at $66 \mathrm{~Hz}$ elicited slow IPSPs, as previously reported (Fiorillo and Williams, 1998). In 15 of 16 randomly selected neurons, superfusion of the slice with the muscarinic receptor antagonist scopolamine $(1 \mu \mathrm{M})$ had little or no effect on the IPSP. In one cell, scopolamine blocked the IPSP. This IPSP appeared distinct from the scopolamine-insensitive IPSPs (mediated by mGluRs) in that it had a relatively short latency to onset. In subsequent experiments, scopolamine was tested only on IPSPs that had a similar, short-onset latency. In all three such cases (of $\sim 50$ cells), scopolamine was effective in blocking the IPSP. An example of a scopolamine-sensitive IPSP is shown in Figure 1. Scopolamine blocked the early component of the IPSP and left a slower mGluR-mediated IPSP. The amplitude of the four scopolamine-sensitive IPSPs was $10.0 \pm 2.5 \mathrm{mV}$, and the latency to peak was $307 \pm 39 \mathrm{msec}$. In contrast, the latency to peak of the mGluR IPSP averaged $\sim 500 \mathrm{msec}$ and was never $<300 \mathrm{msec}$ (Fiorillo and Williams, 1998, their Fig. 1D). Although under the experimental conditions tested scopolamine was rarely effective, it appears that it is possible to evoke cholinergic IPSPs mediated by muscarinic receptors in at least some dopamine neurons. By contrast, slow EPSPs were rarely observed in dopamine neurons with intracellular recording, and when present they are blocked by mGluR antagonists, but not muscarinic receptor antagonists (Shen and Johnson, 1997; Fiorillo and Williams, 1998).

\section{Hyperpolarization to exogenous acetylcholine}

To further investigate the actions of muscarinic receptors on dopamine neurons, acetylcholine (3-30 mM) was applied briefly (3$300 \mathrm{msec}$ ) from patch pipettes by pressure ejection, in the presence of the nicotinic receptor antagonist hexamethonium $(200 \mu \mathrm{M})$. Acetylcholine had both hyperpolarizing and depolarizing actions (Fig. 2A). Short applications resulted in hyperpolarization only (Fig. $2 A$ ), whereas longer applications resulted in a hyperpolarization followed by a longer-lasting depolarization (Fig. 2A). The mechanism of the hyperpolarization was further investigated pharmacologically.

By analogy with previous work on mGluRs in dopamine neurons, we tested apamin, a potent and selective blocker of a subset of small-conductance, calcium-activated potassium channels (SK2 and SK3; Kohler et al., 1996). Apamin (100 nm) effectively blocked the hyperpolarization produced by acetylcholine $(-86 \pm 18 \% ; n=4)$. Voltage-clamp experiments using the whole-cell configuration were used to further characterize the conductance that was activated by acetylcholine. By using an internal solution with minimal calcium buffering capacity, a reproducible hyperpolarizing response to acetylcholine was observed. Acetylcholine applied by iontophoresis induced a short-latency inward current followed by a slower outward current (Fig. 2B). The short-latency inward current was blocked by hexamethonium (data not shown), indicating that it resulted from the activation of nicotinic receptors. The slower outward current was blocked by scopolamine (data not shown). The outward muscarinic current declined in amplitude as the holding potential was shifted to more negative potentials, suggesting that it resulted from the activation of a potassium conductance. The amplitude of nicotinic current increased with hyperpolarization (Fig. 2B,C). Taken together the results suggest that acetylcholine acts on a muscarinic receptor to activate an apamin-sensitive potassium conductance that mediates a hyperpolarization of the membrane potential.

Like the mGluR1 receptors, M1-type muscarinic receptors expressed on dopamine cells (Lacey et al., 1990) are known to induce 

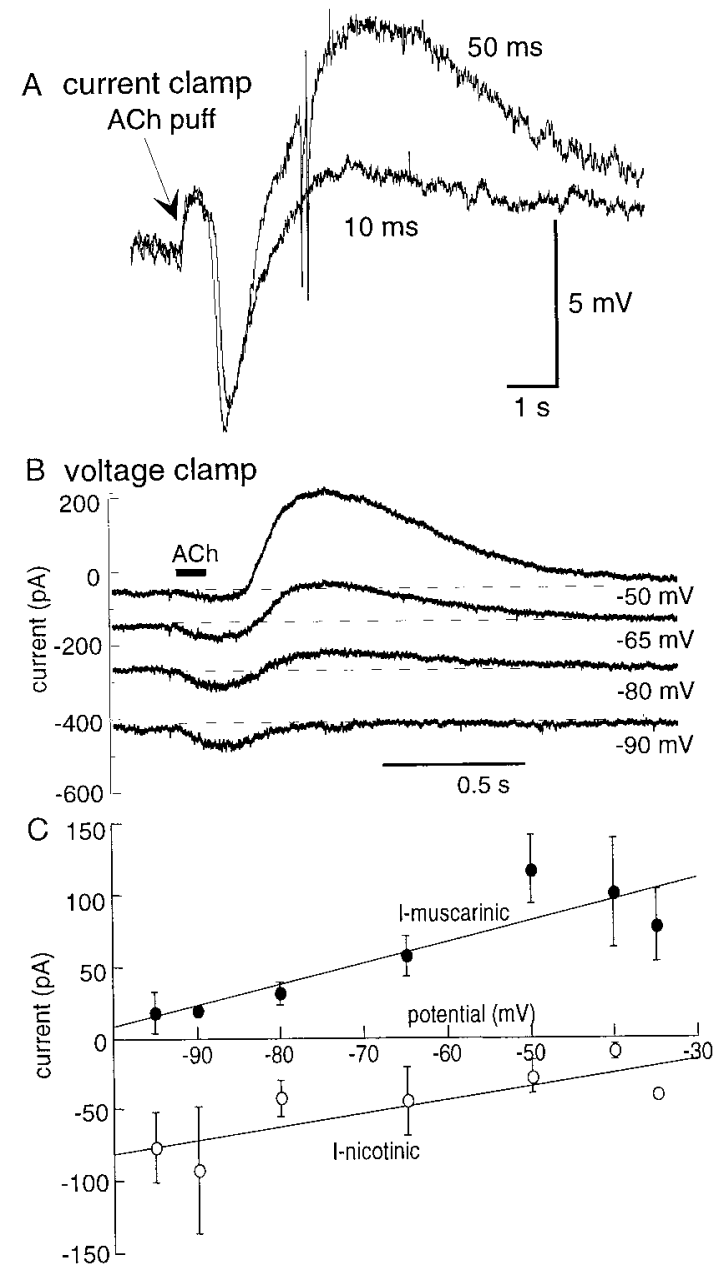

Figure 2. Multiple actions of acetylcholine on dopamine cells. $A$, This is an intracellular recording of membrane potential. Pressure ejection of acetylcholine for $10 \mathrm{msec}$ evoked primarily a hyperpolarization, whereas a 50 msec pulse evoked an equivalent hyperpolarization, followed by a longerlasting depolarization. The depolarization was insensitive to hexamethonium, but was blocked by scopolamine (data not shown). Each trace represents the average of two or three trials. The depolarization in response to $50 \mathrm{msec}$ acetylcholine evoked an action potential on its rising phase, which is diminished in amplitude because of averaging. $B$, This is a whole-cell recording of current obtained in voltage clamp. Iontophoretic application of acetylcholine evoked an early short-latency inward current (nicotinic) followed by a slower outward current (muscarinic). The amplitude of the nicotinic component increased as the membrane potential was held more negative, whereas the outward current decreased in amplitude. $C$, A summary of experiments obtained in voltage clamp as shown in $B$. The amplitude of the nicotinic and muscarinic currents are plotted as a function potential.

calcium release from intracellular stores. The effect of caffeine was used to further characterize the hyperpolarization induced by acetylcholine. Caffeine increases calcium release from intracellular stores, apparently by greatly increasing the calcium sensitivity of the ryanodine receptor (Ehrlich et al., 1994). Superfusion of caffeine $(1 \mathrm{~mm})$ reversibly enhanced the amplitude of acetylcholine hyperpolarizations $(90 \pm 47 \% ; n=4$; Fig. 3$)$. At a higher concentration, caffeine $(10 \mathrm{~mm})$ reversibly inhibited the acetylcholine hyperpolarization $(-73 \pm 9 \%$; $n=6$; Fig. 3 ), presumably by depleting ryanodine-sensitive calcium stores or by blocking the $\mathrm{IP}_{3}$ receptor directly. Ryanodine $(10 \mu \mathrm{M})$, which locks the ryanodine receptor in a subconductance state, depletes calcium stores (Bezprozvanny et al., 1991) and blocked the acetylcholine-induced hyperpolarization measured with intracellular recordings $(-80 \pm$ $7 \% ; n=4)$ and the outward current measured with whole-cell recordings $(-65 \pm 11 \% ; n=6)$. When ruthenium red $(30 \mu \mathrm{M})$, a blocker of the ryanodine receptor, was included in the whole-cell

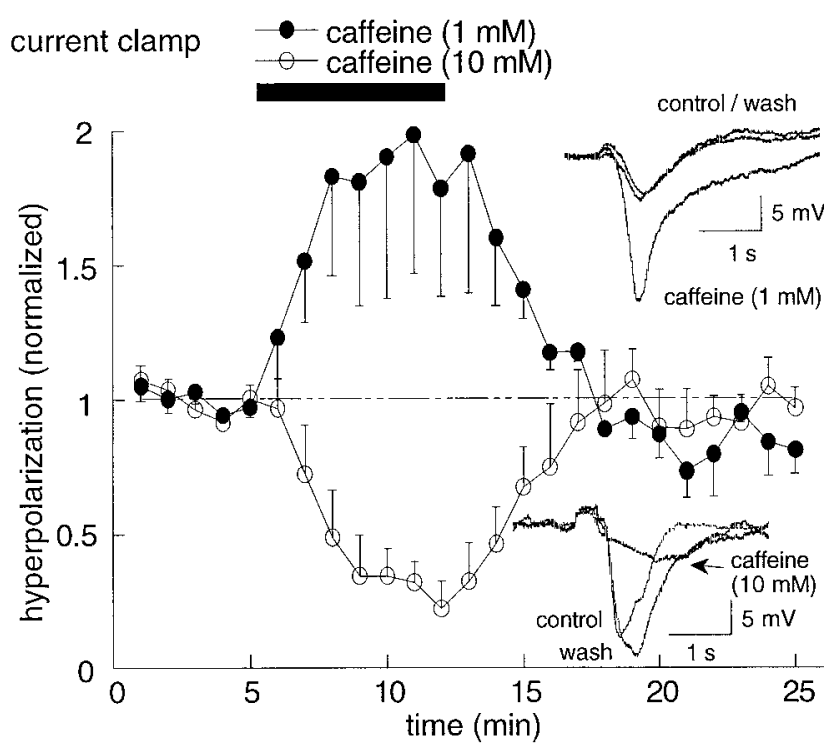

Figure 3. Activation of muscarinic receptors induces calcium release from intracellular stores. Caffeine facilitates and blocks the acetylcholineinduced hyperpolarization, depending on the concentration. These experiments were obtained with intracellular recording of membrane potential. On the left is a plot showing the time course of the facilitation and inhibition of the acetylcholine hyperpolarization induced by caffeine. Each point represents the average amplitude of responses from several cells, each of which was normalized to the average amplitude of the five responses preceding application of caffeine. The control acetylcholine responses were $7.3 \pm 0.9(n=4)$ and $10.7 \pm 1.9(n=5)$ in experiments with 1 and $10 \mathrm{~mm}$ caffeine, respectively. On the right are raw traces illustrating the modulation by caffeine of acetylcholine hyperpolarizations. Each trace is the average of two to four trials. Top, Facilitation by $1 \mathrm{~mm}$ caffeine. Bottom, Inhibition by $10 \mathrm{~mm}$ caffeine.

pipette solution, the outward muscarinic current was not blocked, but the effect of ryanodine was significantly reduced from $-65 \pm$ $11 \%(n=6)$ to $-21 \pm 6 \%(n=4 ; p<0.05)$. The observation that acetylcholine still induced an outward current in the presence of ruthenium red suggests that ryanodine receptors were not required for this muscarinic response. Taken together, the results suggest that muscarinic receptors increase intracellular free calcium by release from a store that is sensitive to depletion by ryanodine but that does not require the activation of ryanodine receptors. Similar results were obtained with ruthenium red in experiments where photolysis of caged- $\mathrm{IP}_{3}$ evoked an increase in intracellular calcium (Morikawa et al., 2000). The conclusion was that the activation of $\mathrm{IP}_{3}$ receptors released calcium from a store that was sensitive to depletion by ryanodine.

\section{Desensitization and depolarization by sustained activation of muscarinic acetylcholine receptors and metabotropic glutamate receptors}

Previous studies, in dopamine and other neurons, have reported depolarization caused by activation of PI-coupled muscarinic receptors. The depolarization was often accompanied by a decrease in potassium conductance. Typically these studies examined responses to sustained activation of muscarinic receptors, and it is possible that under such conditions a calcium-mediated inhibitory response was desensitized. To examine this possibility, voltageclamp experiments were used to determine the effect of a low concentration of muscarine $(300 \mathrm{~nm})$ on the hyperpolarization and outward current induced by rapidly applied acetylcholine. In experiments using intracellular recordings of membrane potential, the hyperpolarizing responses to pressure-applied acetylcholine were reduced by $74 \pm 3 \%(n=4$; Fig. $4 A)$ without significantly altering resting membrane potential $(+1.4 \pm 0.7 \mathrm{mV})$. This concentration of muscarine is approximately tenfold lower than the half-maximal concentration of muscarine effective in depolarizing the membrane (Lacey et al., 1990). In voltage-clamp experiments 

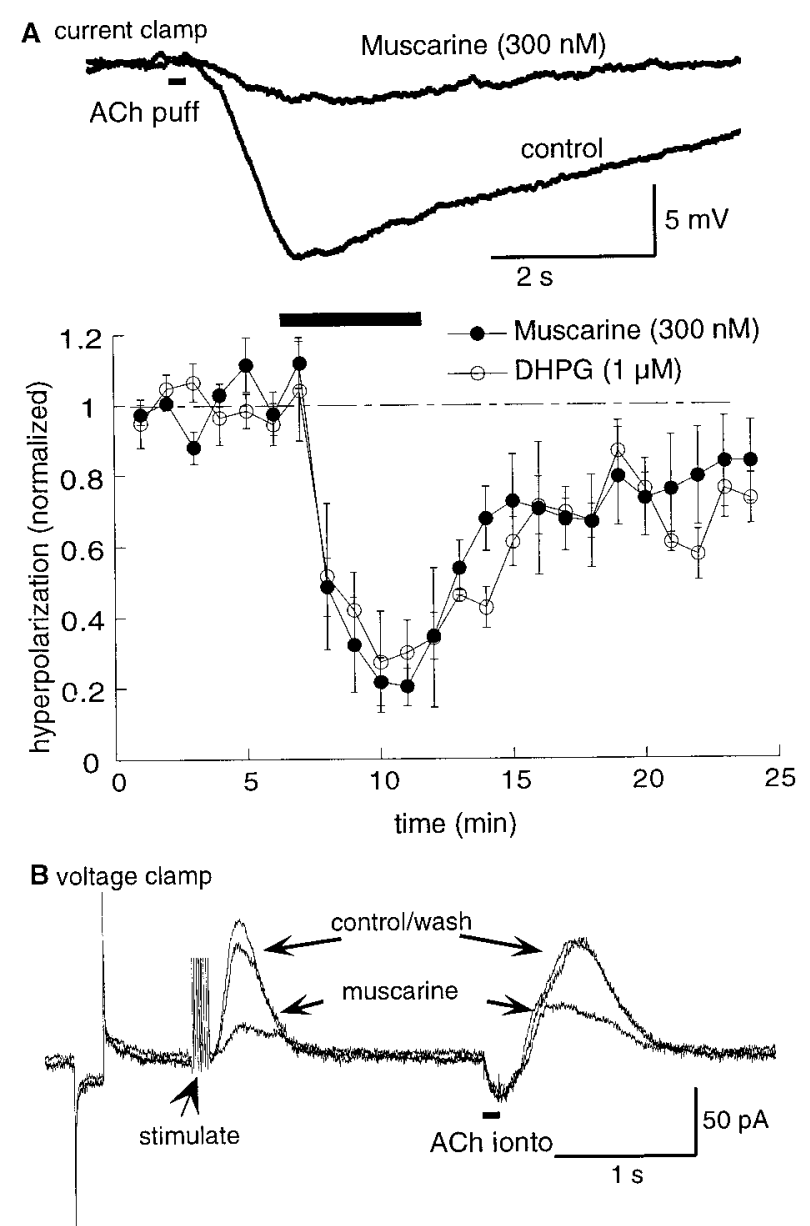

Figure 4. The acetylcholine response is potently blocked by activation of PI-coupled receptors. $A$, An intracellular recording of the hyperpolarization induced by pressure ejection of acetylcholine in the absence (control) and presence of muscarine $(300 \mathrm{nM})$. The plot below is a summary of several similar experiments. Superfusion of a low concentration of muscarine $(300 \mathrm{nM})$ or the mGluR1 agonist DHPG $(1 \mu \mathrm{M})$ almost entirely blocked hyperpolarizations evoked by pressure-applied acetylcholine. Wash of either agonist rapidly produced partial recovery; the remaining desensitization did not recover after $15 \mathrm{~min}$ of wash. The control acetylcholine responses were $6.2 \pm 0.4 \mathrm{mV}(n=4)$ and $6.9 \pm 1.7 \mathrm{mV}(n=5)$ in experiments with muscarine and DHPG, respectively. $B$, A voltage-clamp recording of outward current induced by a synaptically activated mGluR IPSC followed by the outward current induced by iontophoretically applied acetylcholine. The mGluR IPSC and the outward current induced by acetylcholine were dramatically and reversibly reduced during the superfusion of muscarine (300 nM). The nicotinic response was not affected.

with whole-cell recordings, muscarine (300 nM) caused a small inward current $(26 \pm 3 \mathrm{pA} ; n=10)$ and reduced the outward current induced by acetylcholine by $76 \pm 4 \%(n=10$; Fig. $4 B)$.

Because mGluR1 and muscarinic receptors found on dopamine neurons are thought to couple to similar effectors, the effect of superfusion of a low concentration of an mGluR agonist on the muscarinic-induced hyperpolarization was examined. Superfusion of the mGluR1 agonist DHPG $(1 \mu \mathrm{M})$ depolarized the membrane by $3.4 \pm 0.8 \mathrm{mV}$ and reduced the acetylcholine hyperpolarization by $73 \pm 11 \%(n=5$; Fig. $4 B)$. After washing DHPG or muscarine for 10-15 $\mathrm{min}$, the acetylcholine response partially recovered to a new steady-state. Partial recovery was also seen from desensitization of mGluR1-mediated hyperpolarizations by DHPG (Fiorillo and Williams, 1998). Thus, the hyperpolarizing response induced by muscarinic receptor activation was desensitized by a heterologous mechanism.

The effect of muscarine on the outward current induced by mGluRs was used to further examine heterologous desensitization.

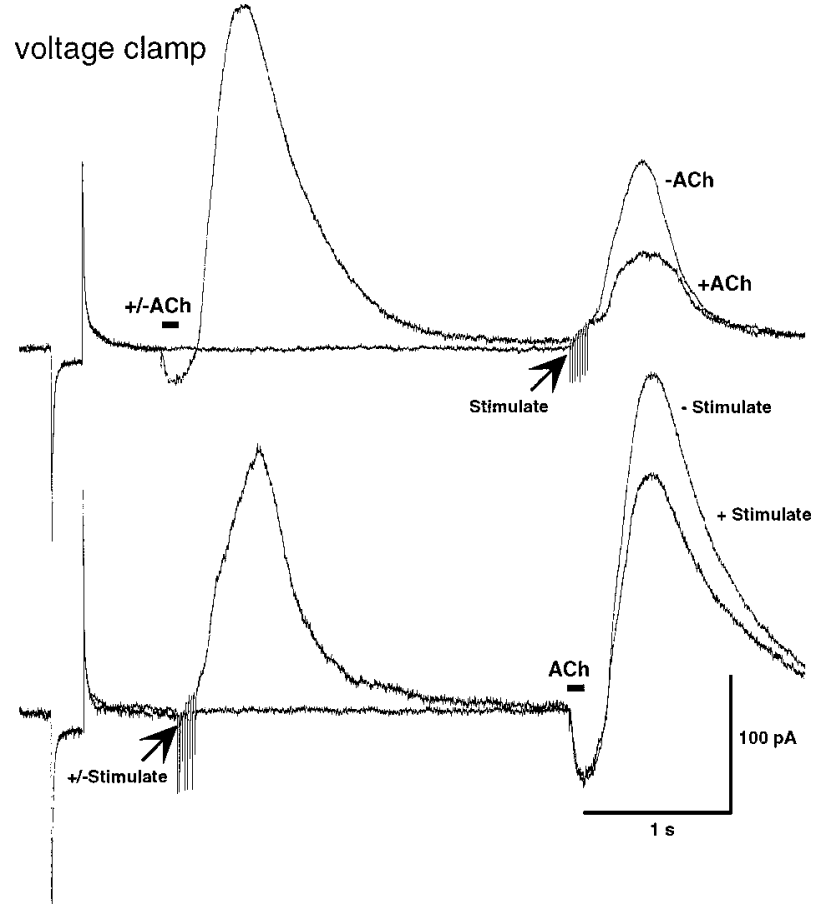

Figure 5. Transient receptor activation causes heterologous desensitization that outlasts the acute response. These are current recordings obtained in the whole-cell configuration. Top, Two superimposed traces showing an example of an experiment in which iontophoretic application of acetylcholine either did nor did not precede the activation of a mGluR IPSC. Bottom, Two superimposed traces in which the protocol was reversed such that an mGluR IPSC preceded the iontophoretic application of acetylcholine. The currents at the beginning of each trace are the response to a step hyperpolarization of $10 \mathrm{mV}(200 \mathrm{msec})$.

The mGluR IPSC was reduced by $72 \pm 9 \%$ (Fig. $4 B ; n=5$ ) by superfusion with muscarine (300 nM). Thus, it appears that continuos activation of either muscarinic receptors or mGluRs with low agonist concentrations results in a potent and reversible heterologous desensitization. The kinetics of heterologous desensitization was examined using the mGluR IPSC and the outward current induced by iontophoretically applied acetylcholine. When acetylcholine was applied $4 \mathrm{sec}$ before a mGluR IPSC was evoked, the amplitude of the IPSC was reduced to $78 \pm 6 \%(n=4)$ of control (Fig. 5). When the protocol was reversed, such that the IPSC was evoked $4 \mathrm{sec}$ before the application of acetylcholine, the outward current in response to acetylcholine was reduced to $81 \pm$ $4 \%(n=4)$ of control. Thus, even a brief activation of either receptor can result in desensitization that outlasts the acute response.

\section{DISCUSSION}

The present results demonstrate that brief activation of muscarinic receptors activated a potassium conductance to hyperpolarize the membrane potential of ventral midbrain dopamine neurons. The outward current was mediated by mobilization of calcium from intracellular stores and activation of an apamin-sensitive potassium conductance. With longer activation of muscarinic receptors, the muscarine-induced outward current desensitized, and an inward current that mediated depolarization was produced. A previous report of the effect of muscarinic agonists on dopamine neurons in vitro found only depolarization (Lacey et al., 1990). This was apparently attributable to the relatively slow and sustained application of agonists, as was found in the present study with superfusion. Muscarinic receptors on dopamine neurons therefore modulate multiple channels to cause either inhibition or excitation, in a manner similar to mGluR1 (Fiorillo and Williams, 1998).

Evidence was presented that the muscarinic inhibition could be 
activated by synaptically released acetylcholine. Although muscarinic IPSPs were observed only in a relatively small fraction of cells, these IPSPs were fairly large $(5-15 \mathrm{mV})$. The reason for the rarity of cholinergic IPSPs is unknown, but may be consistent with cholinergic innervation of a minority of dopamine neurons (Garzon et al., 1999). On the other hand, the increase in potassium conductance in response to exogenously applied acetylcholine was observed in almost every dopamine cell. Thus, it may be that the horizontal sections of the ventral midbrain are not well suited for the activation of afferents from the cholinergic fibers arising from the pedunculopontine nucleus. No muscarinic EPSPs were observed in the present or previous studies (Shen and Johnson, 1997), which is likely attributable to the longer duration of receptor activation necessary to cause depolarization. At most, only very small nicotinic receptor-mediated EPSPs are present in dopamine neurons (J. Dani, personal communication). In spite of the results obtained in brain slices, experiments done in vivo have found that injection of atropine, a muscarinic antagonist, into the VTA increased dopamine release in the nucleus accumbens (E. Munn and R. Wise, personal communication). This could be caused by blockade of cholinergic IPSPs in dopamine neurons.

Like mGluR1, muscarinic receptors produce hyperpolarizing or depolarizing responses in dopamine neurons, depending on the duration of time for which they are active (Fig. $2 A$ ). Desensitization of muscarinic receptor-mediated hyperpolarization occurs after a transient hyperpolarizing response and is almost complete with sustained activation of the receptor. This heterologous desensitization can occur in the absence of any changes in resting membrane potential. Although agonist-induced activation of potassium conductance is almost entirely blocked, activation of the apamin-sensitive afterhyperpolarization (AHP) in dopamine neurons is unaltered by these same agonists (Lacey et al., 1990; Fiorillo and Williams, 1998). Because the apamin-sensitive AHP in dopamine neurons is partially dependent on ryanodine-sensitive calcium stores (our unpublished observations), and assuming a single population of apamin-sensitive channels, it would appear that the desensitization occurs upstream of the ryanodine-sensitive stores. Desensitization could occur through depletion of $\mathrm{IP}_{3}$-sensitive calcium stores (Irving et al., 1992), which are known to be easily depleted in many cell types, and can recover quickly with calcium influx (Berridge, 1998).

The actions of muscarinic receptors (and mGluRs) in dopamine neurons appear similar to their actions in CA1 hippocampal pyramidal neurons. In CA1, muscarinic receptors mediate both hyperpolarizing and depolarizing responses (Segal 1982; Wakamori et al., 1993), and the hyperpolarizing response is dependent on intracellular calcium stores (Wakamori et al., 1993). Studies using slow application of agonist found only excitatory responses (Madison et al., 1987). Desensitization of the hyperpolarizing response has not been examined in the CA1. However, activation of both muscarinic receptors and mGluRs is known to block the slow AHP in these cells (Cole and Nicoll, 1984; Madison et al., 1987; Desai and Conn, 1991). Like the muscarinic hyperpolarization observed in the present study, the slow AHP in CA1 is calcium-dependent, and at least in some types of neurons involves the release of calcium from intracellular stores (Sah and McLachlan, 1991). In CA1 neurons, these calcium-dependent processes are blocked by concentrations of muscarinic agonists that are substantially below those necessary to depolarize the membrane (Cole and Nicoll, 1984; Madison et al., 1987). Thus, it appears to be the case in a number of neuronal types that brief activation of muscarinic receptors hyperpolarized neurons through release of calcium, whereas tonic activation by even very low levels of agonist desensitize this response and in some cells decreased the slow AHP. Stronger receptor stimulation always caused depolarization. Although possible, there is no evidence that these distinct postsynaptic actions of muscarinic receptors (or mGluRs), described in dopamine neurons or CA1 pyramidal neurons, result from activation of distinct receptors.

Cholinergic neurotransmission in the CNS may occur primarily in a diffuse, nonsynaptic fashion, rather than classical point-to- point synaptic transmission (Descarries et al., 1997). It has been hypothesized that, at least in regions of dense cholinergic innervation, an ambient level of acetylcholine is maintained, resulting in tonic activation of receptors (Descarries et al., 1997). It is shown here that tonic activation of muscarinic receptors by low concentrations of agonist blocks the calcium-mediated activation of potassium currents by both muscarinic receptors and mGluRs. To observe inhibition by acetylcholine, the ambient concentration would have to be less than $\sim 30 \mathrm{~nm}$, or else the inhibitory response would be desensitized. This estimate is based on the concentration of acetylcholine that is equipotent to $300 \mathrm{~nm}$ muscarine (concentration used in the present study) in activating a calcium-dependent potassium conductance in dissociated CA1 pyramidal neurons (Wakamori et al., 1993). Quantitative microdialysis performed in the striatum found $18 \mathrm{~nm}$ acetylcholine in the extracellular space (Vinson and Justice, 1997), consistent with levels found in other brain regions (Descarries et al., 1997). Thus, it is suggested that the calcium-dependent potassium conductance is dynamically regulated by acetylcholine, being phasically activated during periods of relatively low cholinergic activity and tonically blocked during periods of sustained cholinergic input. A second potentially important functional consequence of the cholinergic innervation of dopamine cells could be in the modulation of mGluR-mediated inhibition through heterologous desensitization.

\section{REFERENCES}

Berridge MJ (1998) Neuronal calcium signaling. Neuron 21:13-26.

Bezprozvanny I, Watras J, Ehrlich B (1991) Bell-shaped calcium-response curves of Ins $(1,4,5) \mathrm{P}_{3^{-}}$and calcium-gated channels from endoplasmic reticulum of cerebellum. Nature 351:751-754.

Caulfield MP (1993) Muscarinic receptors-characterization, coupling and function. Pharmacol Ther 58:319-379.

Cole AE, Nicoll RA (1984) Characterization of a slow cholinergic postsynaptic potential recorded in vitro from rat hippocampal pyramidal neurons. J Physiol (Lond) 352:173-188.

Colino A, Halliwell JV (1993) Carbachol potentiates Q current and activates a calcium-dependent non-specific conductance in rat hippocampus in vitro. Eur J Neurosci 5:1198-1209.

Desai MA, Conn PJ (1991) Excitatory effects of ACPD receptor activation in the hippocampus are mediated by direct effects on pyramidal cells and blockade of synaptic inhibition. J Neurophysiol 66:40-52.

Descarries L, Gisiger V, Steriade M (1997) Diffuse transmission by acetylcholine in the CNS. Prog Neurobiol 53:603-625.

Ehrlich BE, Kaftlan E, Bezprozvanny S, Bezprozvanny I (1994) The pharmacology of intracellular $\mathrm{Ca}^{2+}$-release channels. Trends Pharmacol Sci 15:145-149.

Fiorillo CD, Williams JT (1998) Glutamate mediates an inhibitory postsynaptic potential in dopamine neurons. Nature 394:78-82.

Garzon M, Vaughan RA, Uhl GR, Kuhar MJ, Pickel VM (1999) Cholinergic axon terminals in the ventral tegmental area target a subpopulation of neurons expressing low levels of the dopamine transporter. J Comp Neurol 410:197-210.

Gronier B, Rasmussen K (1998) Activation of midbrain presumed dopaminergic neurones by muscarinic cholinergic receptors: an in vivo electrophysiological study in the rat. Br J Pharmacol 124:455-464.

Irving AJ, Collingridge GL, Schofield JG (1992) L-glutamate and acetylcholine mobilise $\mathrm{Ca}^{2+}$ from the same intracellular pool in cerebellar granule cells using transduction mechanisms with different $\mathrm{Ca}^{2+}$ sensitivities. Cell Calcium 13:293-301.

Johnson SW, North RA (1992) Two types of neurone in the rat ventral tegmental area and their synaptic inputs. J Physiol (Lond) 450:455-468.

Kitai ST, Shepard PD, Callaway JC, Scroggs R (1999) Afferent modulation of dopamine neuron firing patterns. Curr Opin Neurobiol 9:690-697.

Kohler M, Hirschberg B, Bond CT, Kinzie JM, Marrion NV, Maylie J, Adelman J (1996) Small-conductance, calcium-activated potassium channels from mammalian brain. Science 273:1709-1714.

Lacey MG, Calabresi P, North RA (1990) Muscarine depolarizes rat substantia nigra zona compacta and ventral tegmental neurons in vitro through M1-like receptors. J Pharmacol Exp Ther 253:395-400.

Madison DV, Lancaster B, Nicoll RA (1987) Voltage clamp analysis of cholinergic action in the hippocampus. J Neurosci 7:733-741.

Morikawa H, Imani F, Khodakhah K, Williams JT (2000) Inositol 1,4,5triphosphate-evoked responses in midbrain dopamine neurons. J Neurosci 20:RC103 (1-5). 
Nakajima Y, Nakajima S, Leonard RJ, Yamaguchi K (1986). Acetylcholine raises excitability by inhibiting the fast transient potassium current in cultured hippocampal neurons. Proc Natl Acad Sci USA 83:3022-3026.

Sah P, McLachlan EM (1991) $\mathrm{Ca}^{2+}$-activated K+ currents underlying the afterhyperpolarization in guinea pig vagal neurons: a role for $\mathrm{Ca}^{2+}$ activated $\mathrm{Ca}^{2+}$ release. Neuron 7:257-264.

Scarnati E, Proia A, Compama E, Pacitti C (1986) A microiontophoretic study on the nature of the putative synaptic neurotransmitter involved in the pedunculopontine-substantia nigra pars compacta excitatory pathway of the rat. Exp Brain Res 62:470-478.

Segal M (1982) Multiple actions of acetylcholine at a muscarinic receptor studied in the rat hippocampal slice. Brain Res 246:77-87.

Shen KZ, Johnson SW (1997) A slow excitatory postsynaptic current me- diated by G-protein-coupled metabotropic glutamate receptors in rat ventral tegmental dopamine neurons. Eur J Neurosci 9:48-54.

Vinson PN, Justice JB Jr (1997) Effect of neostigmine on concentration and extraction fraction of acetylcholine using quantitative microdialysis. Neurosci Methods 73:61-67.

Wakamori M, Hidaka H, Akaike N (1993) Hyperpolarizing muscarinic responses of freshly dissociated rat hippocampal CA1 neurones. J Physiol (Lond) 463:585-604.

Williams JT, North RA, Shefner S, Nishi S, Egan TM (1984) Membrane properties of rat locus coeruleus neurones. Neuroscience 13:137-156.

Zhang L, Weiner J, Carlen PL (1992) Muscarinic potentiation of IK in CA1 hippocampal neurons: electrophysiological characterization of the transduction pathway. J Neurosci 12:4510-4520. 